\title{
Intrapopulation niche partitioning in a generalist predator limits food web connectivity
}

\author{
Mario Quevedo, ${ }^{1}$ Richard Svanbäck, and Peter Eklöv \\ Department of Ecology and Evolution (Limnology), Evolutionary Biology Centre, Uppsala University, \\ Husargatan 3, 75123 Uppsala, Sweden
}

\begin{abstract}
Predators are increasingly recognized as key elements in food webs because of their ability to link the fluxes of nutrients and energy between spatially separated food chains. However, in the context of food web connectivity, predator populations have been mainly treated as homogeneous units, despite compelling evidence of individual specialization in resource use. It is conceivable that individuals of a predatory species use different resources associated with spatially separated food chains, thereby decoupling cross-habitat linkages. We tested whether intrapopulation differences in habitat use in the generalist freshwater predator Eurasian perch (Perca fluviatilis) led to long-term niche partitioning and affected the degree of ecological habitat coupling. We evaluated trophic niche variability at successively larger timescales by analyzing gut contents and stable isotopes $\left(\delta^{13} \mathrm{C}\right.$ and $\left.\delta^{15} \mathrm{~N}\right)$ in liver and muscle, tissues that provide successively longer integration of trophic activity. We found that the use of distinct habitats in perch led to intrapopulation niche partitioning between pelagic and littoral subpopulations, consistent through the various timescales. Pelagic fish showed a narrower niche, lower individual specialization, and more stable trophic behavior than littoral fish, as could be expected from inhabiting a relatively less diverse environment. This result indicated that substantial niche reduction could occur in a generalist predator at the subpopulation level, consistent with the use of a habitat that provides fewer chances of individual specialization. We showed that intrapopulation niche partitioning limits the ability of individual predators to link spatially separated food chains. In addition, we suggest a quantitative, standardized approach based on stable isotopes to measure the degree of habitat coupling mediated by a top predator.
\end{abstract}

Key words: Eurasian perch; food webs; habitat coupling; individual specialization; niche partitioning; Perca fluviatilis; stable isotopes; trophic polymorphism.

\section{INTRODUCTION}

Food webs are networks of trophic interactions among organisms. Those networks often include linkages of fluxes of nutrients and energy across habitats that may influence trophic dynamics and food web stability (Huxel and McCann 1998, Vanni 2002). Crosshabitat linkages in food webs (habitat coupling) are widespread in diverse biomes, and have often been attributed to movements of both predators and prey (Polis et al. 1997, Vanni et al. 2004). Recently substantial attention has been devoted to evaluate the importance of predators' role in food web connectivity and stability. Both empirical studies and models suggested that populations of mobile, generalist predators connect the trophic dynamics of spatially separated food chains through predation and excretion of nutrients, and such

Manuscript received 26 September 2007; revised 5 November 2008; accepted 12 November 2008. Corresponding Editor (ad hoc): D. I. Bolnick.

${ }_{1}^{1}$ Present address: Cantabrian Institute of Biodiversity (ICAB), Oviedo University, Departamento Biología Organismos y Sistemas, Campus del Cristo, 33006 Oviedo, Spain. E-mail: quevedomario@gmail.com linkage may enhance food web stability, depending on the intensity of interactions (Hecky and Hesslein 1995, Vadeboncoeur et al. 2005, Rooney et al. 2006). However, the role of predators in food web connectivity has been mostly studied by treating populations as ecologically homogeneous entities, without considering potential effects of intrapopulation variation in the use of habitat and resources.

To study populations of predatory species as homogeneous entities in food webs may be misleading because individual diet specialization relative to the overall population is not rare, and occurs in a broad array of taxa (Bolnick et al. 2003). Furthermore, individual specialization may be more common in predators because of higher incidence of strong intraspecific competition, which is a driver of increased niche variation within populations (Svanbäck and Bolnick 2007), and occurs more often in populations regulated by resources (Estes et al. 2003). Individual specialization may include using distinct, spatially separated resources, and can be due to trade-offs in foraging efficiency in relation to habitat use and morphology (Maynard Smith 1966, Smith and Skúlason 1996, Svanbäck and Eklöv 2003). Hence, individuals of mobile predatory species 
that specialize on resources associated with different habitats may offer a different picture of the role of predators in food web connectivity, because of the potential development of stable intrapopulation niche partitioning. Such partitioning may limit their efficiency to link the fluxes of energy and nutrients across spatially separated food chains, although this is an understudied aspect of food web dynamics.

Lakes provide appropriate systems to study the interplay between individual specialization and differential habitat use because their habitats differ markedly in both physical structure and food chain properties (Schindler and Scheuerell 2002). The base of pelagic food chains, associated with offshore, open-water habitats, is characterized by much smaller particle sizes than those of littoral food chains associated with nearshore, often vegetated habitats (Havens 1997, Schindler and Scheuerell 2002). Pelagic environments can be expected to show lower ratios of predator to prey species, and a lower proportion of top predator species in the species assemblages relative to littoral environments (Havens 1997). In addition, pelagic production may be less efficiently transferred to predators (Vander Zanden et al. 2006). Hence, the distinct food chain properties associated with pelagic and littoral habitats of lakes provide considerable potential for ecological divergence, particularly in mobile predators (e.g., Futuyma and Moreno 1988, Schluter 1996, Barluenga et al. 2006). In lakes, those top predators are often fish. Many fish species, including those normally considered pelagic, rely strongly on littoral resources (Vander Zanden and Vadeboncoeur 2002). Because of the overall strong reliance on littoral resources and their presumed mobility, fish have been identified as key couplers of pelagic and littoral food chains. Their trophic activity may influence the composition and dynamics of prey in both habitats, and the regulation of fluxes of nutrients and energy (Hecky and Hesslein 1995, Schindler and Scheuerell 2002). Therefore, fish species in lakes could play a strong coupling and stabilizing role in food webs, predicted by theory (Vadeboncoeur et al. 2005, Rooney et al. 2006).

In this study, we hypothesized that pelagic fish exploit a relatively more homogeneous environment with a less diverse prey community, participating in fewer trophic interactions. Therefore, we expected them to show less morphological variation and narrower and less variable trophic niches. We tested whether the habitat use by individuals of a predatory species leads to long-term intrapopulation niche partitioning, and evaluated whether niche partitioning could in turn affect the degree of ecological habitat coupling. We studied a population of Eurasian perch (Perca fluviatilis L.), a widespread freshwater fish. Eurasian perch is a predatory species that often exerts a strong impact on lake food webs (Persson et al. 2003). Perch use both the pelagic and littoral habitats of lakes, and show continuous phenotypic variation in relation to habitat use (Svanbäck and Eklöv 2002, 2003). Additionally, individuals have relatively higher feeding performances, grow faster in their respective habitats, and show adaptive plasticity in both general body shape and in gut length associated with habitat and resource use (Svanbäck and Eklöv 2003, 2006, Olsson et al. 2007). Therefore, Eurasian perch is an appropriate model species for the objectives of our study.

Using two distinct techniques, we were able to study the trophic ecology of perch over different timescales: analysis of gut contents gave direct information about immediate diet, whereas indirect information of trophic activity was derived from analyses of stable isotopes in tissues with successively longer retention times, i.e., the liver (medium term) and muscle (longer term). The stable isotopes technique provides integrative, standardized variables like trophic position (Vander Zanden et al. 1999, Post 2002), or the proportional reliance of consumers on given resources (Newsome et al. 2007), which help in the interpretation of the individual isotopic values in a food web context. We used trophic position and reliance on the littoral to estimate niche overlap and habitat coupling.

\section{Methods}

The study was carried out in summer 2004 in Lake Björklinge Långsjön (Uppland, Sweden; 6003' N, $17^{\circ} 35^{\prime} \mathrm{E}$ ). Björklinge Långsjön is an oligotrophic lake with $20.3 \mu \mathrm{g} / \mathrm{L}$ of average total phosphorus, a surface area of $2.5 \mathrm{~km}^{2}$, and maximum and mean depths of $12.5 \mathrm{~m}$ and $6.3 \mathrm{~m}$, respectively. Test fishing in the lake yielded 11 species (P. Eklöv and R. Svanbäck, unpublished data): Eurasian perch, zander (Sander lucioperca L.), ruffe (Gymnocephalus cernuus L.), northern pike (Esox lucius L.), burbot (Lota lota L.), roach (Rutilus rutilus L.), rudd (Scardinius erythrophthalmus L.), bleak (Alburnus alburnus L.), tench (Tinca tinca L.), common bream (Abramis brama L.), and white bream (Blicca bjoerkna L.).

We used standardized multimesh gill nets to catch fish both in the littoral and the pelagic zones (maximum depth $12 \mathrm{~m}$ ) of the lake. Nets were $30 \mathrm{~m}$ long and $1.5 \mathrm{~m}$ deep, and were set overnight on 1 September 2004, catching 29 littoral and 53 pelagic perch. The most common species was roach, which constituted $43 \%$ and $64 \%$ by biomass of the catch in the littoral and pelagic nets, respectively. However, we studied the perch population because of its much stronger predatory role in lake communities and its consistent trophic polymorphism (Svanbäck and Eklöv 2002, 2003, Persson et al. 2003, Svanbäck and Persson 2004). Perch were cooled on dry ice until arrival at the laboratory. Subsequently, fish were measured to the nearest $1 \mathrm{~mm}$ (standard length), weighed to the nearest $0.1 \mathrm{~g}$, and stored frozen at $-20^{\circ} \mathrm{C}$. The residuals of predicted mass from the $\log ($ length $)-\log$ (mass) linear regression were used as an index of body condition $\left(n=82, R^{2}=0.992, P<\right.$ $0.0001)$. 

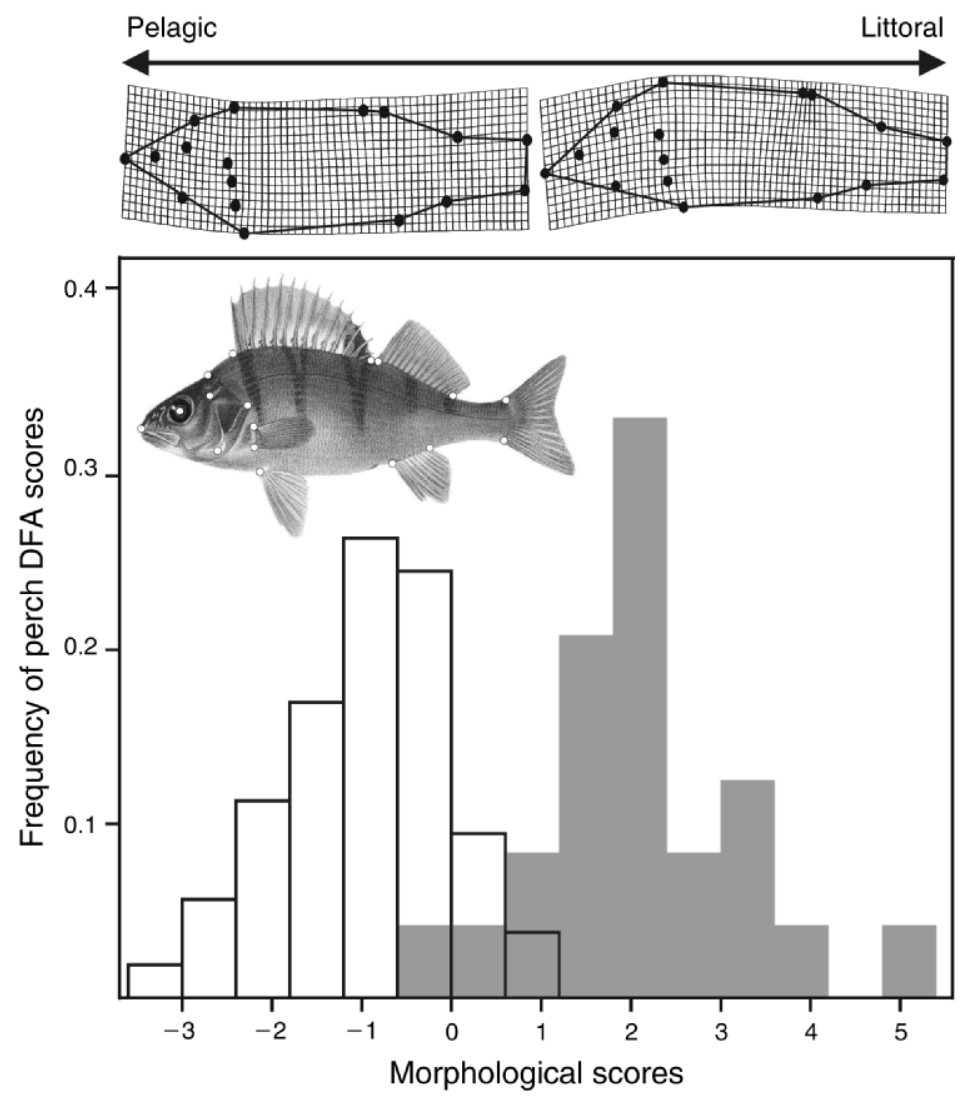

FIG. 1. Upper graph: Landmarks used to analyze morphology of the Eurasian perch, Perca fluviatilis, and deformation plots (uniform and nonuniform components) corresponding to both ends of the pelagic-littoral continuum. Lower graph: frequency distribution of perch DFA morphological scores. Open and solid bars show pelagic and littoral fish, respectively.

\section{Morphological analyses}

Fish morphology was analyzed using landmark-based thin-plate spline (TPS) analysis, a geometric morphometrics technique (Zelditch et al. 2004). TPS is a powerful analysis of shape variation that demonstrates shape changes among individuals as a deformation over the entire form. To conduct the analyses fish were thawed and then photographed, and 17 landmarks were digitized on their left side (Fig. 1). We used the digitized landmarks (2-D coordinates) to analyze the relative position of these landmarks and variation in body shape using tpsRelw v.1.42 (Rohlf 2005a), calculating uniform and nonuniform (partial warps) components of deformation of each individual. The uniform component of deformation describes all shape variation that is uniform throughout the whole geometry of the animal, i.e., variation that is neither spatially localized nor spatially disproportionate. The nonuniform deformations or partial warps describe spatially graded variations and those that are highly localized to particular regions of an animal's geometry (Zelditch et al. 2004).

A discriminant function analysis (DFA) was used to assign individuals to habitats. DFA combines all partial warp and uniform scores into a single morphological index for each fish, i.e., the scores of the discriminant function, which maximally discriminates between the two habitats. The software package tpsRegr v. 1.31 (Rohlf 2005b) was used to visualize shape variation as total fish deformation among pelagic and littoral individuals.

\section{Diet data analyses}

The stomach contents of perch were analyzed under a dissecting microscope, and the contents were classified following the identification scheme set out in Svanbäck and Persson (2004). Perch diet width $(W)$ was estimated as

$$
W=\frac{1}{\sum p_{j}^{2}}
$$

where $p_{j}$ is the proportion of the diet that is represented by diet category $j$. The index has a minimum at 1 when only one prey type is found in the diet, and a maximum at $n$ equal to the total number of prey categories when each prey type is equally apportioned in the diet of the individuals. $W$ was calculated from the average proportion of each prey category in each subpopulation's diet. To obtain a null distribution of $W$ and test 
the significance differences between subpopulations, we randomized the empirical diet data set 1000 times and calculated $W$ in each iteration. $P$ values were approximated as the proportion of resampled data sets that exceeded the observed differences (Gotelli and Ellison 2004). The diet breadth of each littoral and pelagic individual $\left(W_{i}\right)$ was calculated from the proportion of each prey category in the individual's diet.

Diet specialization was estimated by means of the proportional similarity index $\left(\mathrm{PS}_{i}\right)$, which measures the diet overlap between an individual and its population:

$$
\mathrm{PS}_{i}=\sum_{j} \min \left(\mathrm{p}_{i j}, q_{j}\right)
$$

where $p_{i j}$ is the proportion of diet category $j$ in the diet of the individual $i$, and $q_{j}$ is the proportion of diet category $j$ in the population as a whole. $\mathrm{PS}_{i}$ tends to 1 when the diet of an individual is similar to that of the population, whereas it is $q_{j}$ in individuals that specialize on a single diet item $j$ (Bolnick et al. 2002). We used the inverse of the average similarity index, 1 - IS, to estimate the overall prevalence of individual specialization in the pelagic and littoral subpopulations.

\section{Stable isotope analyses}

We used stable isotopes to separate the variability of the diet into short- and long-term components by measuring isotopic variability in tissues that have different turnover rates (i.e., tissues that provide trophic information over different timescales). The stable isotope ratios of carbon and nitrogen $\left(\delta^{13} \mathrm{C}\right.$ and $\left.\delta^{15} \mathrm{~N}\right)$ were used in this study due to their ability to discriminate between pelagic or littoral resources, and differential trophic positions (Fry 1988, France 1995). The isotopic signature of primary producers is often highly variable; hence, tissues of primary consumers may be used as an alternative to obtain time-integrated values of the carbon and nitrogen sources at the base of the food web (Vander Zanden and Rasmussen 1999). To obtain the littoral $\delta^{13} \mathrm{C}$ and $\delta^{15} \mathrm{~N}$ baseline signatures, snails (Lymnaea peregra Müller) were collected in July and September 2004 from reed stems. The pelagic baseline signature was obtained by averaging zooplankton samples collected with a $100-\mu \mathrm{m}$ mesh net on 4 June, 6 July, and 19 August 2004. Benthic macroinvertebrates and cladocerans were sampled on 4 June, 6 July, and 19 August 2004 by scraping the bottom with a square-framed net $(500 \mathrm{~mm})$. All samples were frozen on dry ice immediately after collection, and were thawed and sorted in the laboratory under a dissecting microscope. Snail foot muscle tissue and zooplankton samples were cleaned of periphyton or detritus and phytoplankton, respectively. All samples were oven dried for $48 \mathrm{~h}$ at $60^{\circ} \mathrm{C}$.

Portions of dorsal muscle and liver were dissected from the littoral and pelagic perch $(n=29$ and 39 , respectively, representing the entire littoral catch and a random selection of $75 \%$ of the pelagic catch) and frozen at $-20^{\circ} \mathrm{C}$. Dorsal muscle was similarly used to obtain the isotopic signature of potential prey fish (bleak, roach, and common bream, $n=86$ ). Tissue samples were oven dried for $48 \mathrm{~h}$ at $60^{\circ} \mathrm{C}$ and ground to a fine powder using a mortar and pestle. Lipids were not removed from the samples to avoid potential derived artifacts (Pinnegar and Polunin 1999). However, $\delta^{13} \mathrm{C}$ values from liver were corrected for lipid bias following Post et al. (2007). Muscle values were not corrected because their average $\mathrm{C}: \mathrm{N}$ was 3.3 , a value consistent with the expected low lipid content of dorsal muscle (Pinnegar and Polunin 1999, Post et al. 2007).

Dried samples $(1 \pm 0.2 \mathrm{mg})$ were packed into $6 \times$ $4 \mathrm{~mm}$ tin capsules for $\delta^{13} \mathrm{C}$ and $\delta^{15} \mathrm{~N}$ analyses, which were performed using a continuous-flow isotope ratio mass spectrometer at UC Davis Stable Isotope Facility (Davis, California, USA). Stable isotope ratios $\left(\delta^{13} \mathrm{C} / \delta^{15} \mathrm{~N}\right)$ are expressed as parts per thousand deviation from standard material, Pee Dee belemnite limestone for $\delta^{13} \mathrm{C}$, and atmospheric nitrogen for $\delta^{15} \mathrm{~N}$. A quarter of the samples were analyzed in duplicate, and the analytical error was $0.12 \%$ for $\delta^{15} \mathrm{~N}$ and $0.09 \%$ for $\delta^{13} \mathrm{C}$.

The trophic position and dietary proportion of littoral resources of each individual were estimated from the isotopic values of muscle tissue, using a two end-member mixing model that incorporated community average stepwise enrichment in $\delta^{13} \mathrm{C}$, and the relative contribution of benthic and pelagic pathways to perch signatures (Quevedo and Olsson 2006). The average signatures of Lymnaea snails and zooplankton were used as end members. These transformations render biological interpretations of the isotopic signatures, i.e., trophic position for $\delta^{15} \mathrm{~N}$ and proportion of littoral reliance for $\delta^{13} \mathrm{C}$, which are independent of the system-specific baseline signatures and allow cross-ecosystem comparisons.

\section{Trophic niche width and variability}

We estimated trophic niche variability of perch from stable isotope ratios in liver and dorsal muscle, tissues that normally show different turnover rates because of their differential metabolic activity (de la Higuera et al. 1999). These differences in turnover rate imply that the isotopic signatures of prey will be integrated into liver and muscle tissue over different periods, and thus can be used to complement the information provided by gut content analyses (Tieszen et al. 1983, Newsome et al. 2007). However, tissue turnover rates depend on species, body size, and trophic status, and so does the time window covered by the analysis of stable isotopes. In fish, sand gobies Pomatoschistus minutus showed ${ }^{13} \mathrm{C}$ average retention times of about two weeks in liver and one month in muscle (Guelinckx et al. 2007), whereas Nile tilapia Oreochromis niloticus, about twice the size of the sand gobies, showed ${ }^{13} \mathrm{C}$ average retention times that varied as a function of the food ration from about two weeks to a month in liver, and two to five months in muscle (S. A. Carleton and C. Martínez del Rio, personal communication). In perch, we recorded a ${ }^{13} \mathrm{C}$ average retention time of 1.5 months in the muscle of 5 -g fish fed 
ad libitum (M. Quevedo, unpublished data). These values correspond to fish comparable to those from the lower end of the size distribution of the fish in our study, and therefore represent minimum estimates of the time window of diets covered by stable isotopes. This dualtissue isotopic approach, together with the detailed but snapshot-like information obtained from the gut contents, permits a time-integrated view of the trophic ecology of the fish.

To calculate trophic niche breadth and structure, we used quantitative metrics based on the position of individuals in the $\delta^{13} \mathrm{C}-\delta^{15} \mathrm{~N}$ space and Euclidean distances (Layman et al. 2007a). Layman et al. (2007a) described and applied the metrics at the community level, where species are the reference. We applied such metrics at the population level, using individuals in the different subpopulations as measurement units. To estimate the total niche space occupied by pelagic or littoral subpopulations, we measured the total area (TA) of a convex hull that included the isotopic values of either pelagic or littoral perch. To obtain null distributions of TA and test the significance of differences between subpopulations, we randomized the empirical data set of isotopic signatures 1000 times and calculated TA in each resampled data set. $P$ values were approximated as the proportion of resampled data sets that exceeded the observed differences. We repeated this procedure with subsets of $50 \%$ of the individuals to evaluate the influence of extreme values on TA estimates.

To estimate the trophic variability within subpopulations we calculated Euclidean distances among individuals in the $\delta^{13} \mathrm{C}-\delta^{15} \mathrm{~N}$ bi-plot. First, we calculated the distance of each individual to the isotopic centroid of its subpopulation (CD), providing an index of the trophic diversity within each subpopulation. The centroid is the mean $\delta^{13} \mathrm{C}$ and $\delta^{15} \mathrm{~N}$ of the individuals in the subpopulation. Then we calculated the coefficient of variation of the distances from each individual to its neighbors in the isotopic space (CVND), which gives a measure of trophic evenness. We used the distances from an individual to all neighbors rather than the nearest neighbor distance suggested by Layman et al. (2007a) because, if the data are aggregated in several clusters, the distance to a single, nearest neighbor does not represent this clustering and consequently yields an inaccurate mean and deviation.

To test differences in diet consistency between pelagic and littoral perch, we delineated the vectors connecting the isotopic values of liver (shorter integration time) and muscle (longer integration time) of each individual, and calculated their azimuths using the $\delta^{15} \mathrm{~N}$ axis as reference. We compared the variances of these azimuths between subpopulations. Lower relative variability of azimuths can be interpreted as higher consistency of individual diets over time.

To estimate niche overlap we delineated convex hulls enclosing the values in the trophic position-littoral reliance bi-plot. Trophic position and littoral reliance are transforms of the $\delta^{13} \mathrm{C}$ and $\delta^{15} \mathrm{~N}$ values that incorporate the baseline isotopic signatures of pelagic and littoral food webs, thus allowing cross-ecosystem comparisons (e.g., Newsome et al. 2007).

$\mathrm{CD}, \mathrm{CVND}$, and azimuths were calculated with ArcView GIS 3.2 (ESRI, Redlands, California, USA). Convex hulls and TA were calculated using package Adehabitat (Calenge 2006), an extension to R statistical environment (R Development Core Team 2008), which we used for all the statistical analyses.

\section{Isotopic source proportions}

The isotopic signatures of food sources can be used to estimate the proportional contribution of each source to the assimilated diet of consumers. In general, the signatures of $n$ isotopes are required to obtain a unique solution for the proportional contributions of $n+1$ sources. In the case of a system exceeding $n+1$ sources, the software IsoSource v. 1.3 (Phillips and Gregg 2003) generates a distribution of all the feasible solutions for a given isotopic mixture. This iterative approach depends on the sampling scheme used for the potential prey, the mixing polygon obtained, and the values of trophic fractionation chosen. We used IsoSource and the mean values of $\delta^{13} \mathrm{C}$ and $\delta^{15} \mathrm{~N}$ from four different sources to estimate the most likely proportional contributions to the average isotopic signatures of littoral and pelagic perch. Those sources were zooplankton, littoral macroinvertebrates, benthic cladocerans, and fish (bleak, bream, and roach). Mean isotopic values of the sources were corrected for trophic fractionation prior to input in IsoSource, assuming community-wide values of $0.47 \%$ for $\delta^{13} \mathrm{C}$ and $3.40 \%$ for $\delta^{15} \mathrm{~N}$ (Post 2002). Those combinations that approximated the average isotopic signatures of fish within a range of tolerance of $\pm 0.05 \%$ in $1 \%$ increments were considered feasible solutions. These analyses are not intended to be hard estimates of actual diets, but rather to give a picture of the potential contribution of food sources to account for the observed isotopic differences between perch subpopulations.

\section{Results}

\section{Fish morphology}

Median length of the littoral perch was $95 \mathrm{~mm}$ (interquartile range $=37 \mathrm{~mm}$ ), whereas median length of pelagic perch was $104 \mathrm{~mm}$ (interquartile range $=43$ $\mathrm{mm})$. There were no differences in body condition between littoral and pelagic perch (one-way ANOVA, $\left.F_{1,66}=0.61, P=0.44\right)$. The DFA correctly classified $96 \%$ of the individuals to their respective habitat (Wilks' $\lambda=$ $0.32, F_{30,46}=3.26, P=0.0002$ ). Morphological analysis yielded substantial differentiation between pelagic and littoral perch subpopulations. The uniform component of deformation showed that perch caught in the littoral zone had a more rounded body, whereas partial warps showed downward shape, steeper frontal slope, and longer dorsal fin compared with perch caught in the pelagic zone (Fig. 1). The DFA morphological scores 

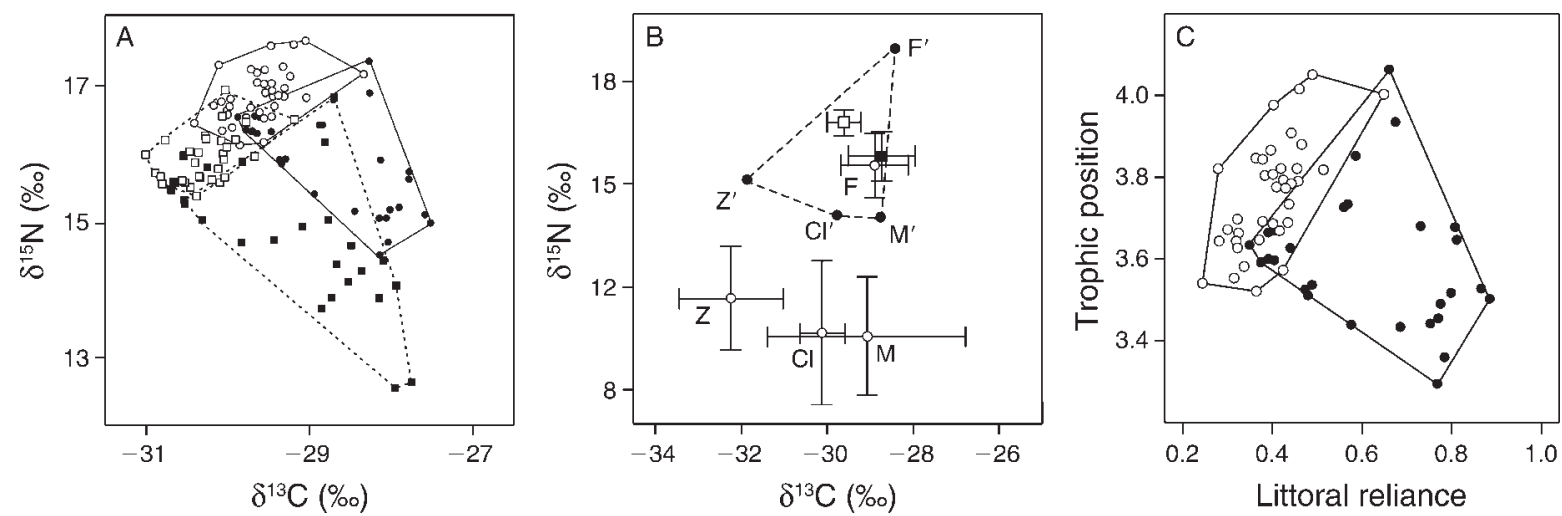

FIG. 2. (A) Isotopic signatures of liver (squares) and muscle (circles) tissues of littoral perch (solid symbols) and pelagic perch (open symbols). The lines enclosing individual values show the convex hulls used to estimate total niche width. (B) Isotopic values (mean $\pm \mathrm{SD}$ ) of perch and potential prey according to the IsoSource modeling of isotopic source proportions (Phillips and Gregg 2003). Solid and open squares show littoral and pelagic perch signatures, respectively. Open circles show average signatures of zooplankton $(\mathrm{Z})$, benthic cladocerans $(\mathrm{Cl})$, littoral macroinvertebrates $(\mathrm{M})$, and fish $(\mathrm{F})$. Solid circles show the end-members used $\left(\mathrm{Z}^{\prime}, \mathrm{Cl}^{\prime}, \mathrm{M}^{\prime}, \mathrm{F}^{\prime}\right)$ with IsoSource, i.e., average signatures corrected for trophic fractionation. The dashed line shows the mixing polygon of the food sources. (C) Trophic position vs. proportion of reliance on littoral resources. The trophic position (i.e., the average position relative to primary producers at which an organism feeds) and the littoral reliance (i.e., the proportion of assimilated resources obtained from the littoral habitat) are indices estimated from the isotopic values of muscle tissue (see Methods: Stable isotope analyses for details). The convex hulls enclosing individual values were used to estimate niche overlap between littoral perch (solid symbols) and pelagic perch (open symbols).

were less variable in pelagic than littoral perch (Fisher's $F$ test; $\left.F_{25,23}=2.84, P=0.014\right)$.

\section{Isotopic signatures}

The baseline $\delta^{13} \mathrm{C}$ of the littoral food chain in Lake Långsjön was $4.5 \%$ higher than the pelagic. Conversely, the baseline $\delta^{15} \mathrm{~N}$ of the pelagic food chain was 2.1\% higher than the littoral (one-way ANOVAs; $F_{1,12}=39.1$, $P<0.001$, and $F_{1,12}=5.0, P=0.045$, respectively). The intrinsic variability of isotopic end-members in the pelagic and littoral habitats was similar. $F$ tests showed that differences in variability between zooplankton and Lymnaea sp. snails were not significant (Fisher's $F$ tests; $F_{10,2}=15.2, P=0.13$ and $F_{10,2}=4.12, P=0.42$ for $\delta^{13} \mathrm{C}$ and $\delta^{15} \mathrm{~N}$, respectively). Similarly, differences between the filter-feeding mussel Dreissena polymorpha (longlived, baseline counterpart of zooplankton) vs. Lymnaea were not significant $\left(F_{4,2}=6.4, P=0.28\right.$ and $F_{4,2}=1.3, P$ $=0.96$, for $\delta^{13} \mathrm{C}$ and $\delta^{15} \mathrm{~N}$, respectively).

The overall isotopic difference between muscle and liver in perch was $1.2 \%$ for $\delta^{13} \mathrm{C}$ and $1.01 \%$ for $\delta^{15} \mathrm{~N}$. Littoral perch showed higher $\delta^{13} \mathrm{C}$ and lower $\delta^{15} \mathrm{~N}$ than pelagic perch (Fig. 2A, B). These differences were highly significant both in muscle and liver (ANCOVAs with $\log \left(\right.$ length) as covariate; Table 1). Values for $\delta^{13} \mathrm{C}$ of both littoral and pelagic perch correlated positively to fish length, whereas for $\delta^{15} \mathrm{~N}$, the relationship was only significant in pelagic perch (Table 2; Fig. 3). The interaction between habitat and perch length was only significant for $\delta^{13} \mathrm{C}$ of muscle tissue (Table 1).

Pelagic perch showed higher average trophic position than littoral perch (3.76 and 3.60, respectively; ANCOVA with $\log$ (length) as covariate, $F_{1,63}=18.9, P<$ $0.0001)$. The interaction between habitat and $\log$ (length) was not significant $\left(F_{1,62}, P=0.12\right)$.

\section{Trophic niche width and variability}

The population diet breadth $W$ was significantly smaller in pelagic than in littoral perch (nonparametric permutation test, $P=0.018$; Table 3 ). There were no differences in individual diet breadth $W_{i}$ between subpopulations. Average individual specialization $1-$ IS was lower in pelagic than littoral perch (KruskalWallis test, $P<0.001$; Table 3). In littoral perch, we found that diet similarity $\mathrm{PS}_{i}$ was inversely related to the individual morphological scores, indicating that deeper

TABLE 1. Results of ANCOVAs ( $F$ values) for isotopic signatures, comparing littoral and pelagic subpopulations of Eurasian perch (Perca fluviatilis) with $\log ($ length) as covariate.

\begin{tabular}{lcccc}
\hline \hline \multicolumn{1}{c}{ Source } & $\delta^{13} \mathrm{C}_{\text {muscle }}$ & $\delta^{15} \mathrm{~N}_{\text {muscle }}$ & $\delta^{13} \mathrm{C}_{\text {liver }}$ & $\delta^{15} \mathrm{~N}_{\text {liver }}$ \\
\hline Habitat & $50.8^{* * *}$ & $54.8^{* * *}$ & $40.6^{* * *}$ & $34.4^{* * *}$ \\
log(length) & $22.6^{* * *}$ & $6.2^{*}$ & $14.5^{* * *}$ & $\mathrm{NS}$ \\
Habitat $\times \log ($ length $)$ & $4.4^{*}$ & $\mathrm{NS}$ & $\mathrm{NS}$ & $\mathrm{NS}$ \\
df & 1,62 & 1,63 & 1,53 & 1,54 \\
\hline
\end{tabular}

* $P<0.05 ; * * * P<0.001 ;$ NS, not significant. 
TABLE 2. Summary of isotopic signatures of perch muscle and liver tissue in Lake Långsjön, Sweden (adjusted mean \pm SE), and minimum adequate ANCOVAs with $\log$ (length) as covariate.

\begin{tabular}{|c|c|c|c|c|c|c|c|}
\hline \multirow[b]{2}{*}{ Tissue } & \multirow[b]{2}{*}{$N$} & \multicolumn{3}{|c|}{$\delta^{13} \mathrm{C}$} & \multicolumn{3}{|c|}{$\delta^{15} \mathrm{~N}$} \\
\hline & & Mean $\pm \mathrm{SE}$ & Intercept & Slope & Mean $\pm \mathrm{SE}$ & Intercept & Slope \\
\hline \multicolumn{8}{|l|}{ Muscle } \\
\hline $\begin{array}{l}\text { Littoral perch } \\
\text { Pelagic perch }\end{array}$ & $\begin{array}{l}29 \\
39\end{array}$ & $\begin{array}{l}-28.60 \pm 0.10 \\
-29.66 \pm 0.09\end{array}$ & $\begin{array}{l}-36.57 \\
-33.00\end{array}$ & $\begin{array}{l}4.07 \\
1.71\end{array}$ & $\begin{array}{l}15.89 \pm 0.10 \\
16.79 \pm 0.09\end{array}$ & $\begin{array}{l}13.10^{* * *} \\
14.00^{* * *}\end{array}$ & 1.43 \\
\hline \multicolumn{8}{|l|}{ Liver } \\
\hline $\begin{array}{l}\text { Littoral perch } \\
\text { Pelagic perch }\end{array}$ & $\begin{array}{l}25 \\
33\end{array}$ & $\begin{array}{l}-29.13 \pm 0.14 \\
-30.37 \pm 0.13\end{array}$ & $\begin{array}{l}-34.85^{* * *} \\
-36.10^{* * *}\end{array}$ & 2.92 & $\begin{array}{l}14.74 \pm 0.15 \\
15.90 \pm 0.13\end{array}$ & $\begin{array}{l}\cdots \\
\cdots\end{array}$ & $\begin{array}{l}\cdots \\
\cdots\end{array}$ \\
\hline
\end{tabular}

Notes: Asterisks $(* * *)$ indicate significant differences $(P<0.001)$ between intercepts in the fitted model. The common slope is shown where appropriate. $F$ values and degrees of freedom are shown in Table 1.

bodied individuals in the littoral habitat specialize more than streamlined individuals (Kendall's rank correlation, $\tau=-0.38, P=0.022$ ). We did not find a diet similarity-morphology correlation in pelagic perch (Kendall's rank correlation, $\tau=0.23, P=0.92$; Fig. 4).

Nonparametric permutation tests showed that the total niche space (TA) of pelagic perch was significantly smaller in both muscle and liver (Fig. 2A, Table 3). CD was significantly shorter in pelagic than littoral perch, both for muscle and liver, whereas differences in CVND were not significant (Kruskal-Wallis tests; Table 3). The variability of the azimuths between the isotopic values of liver and muscle was lower in pelagic vs. littoral
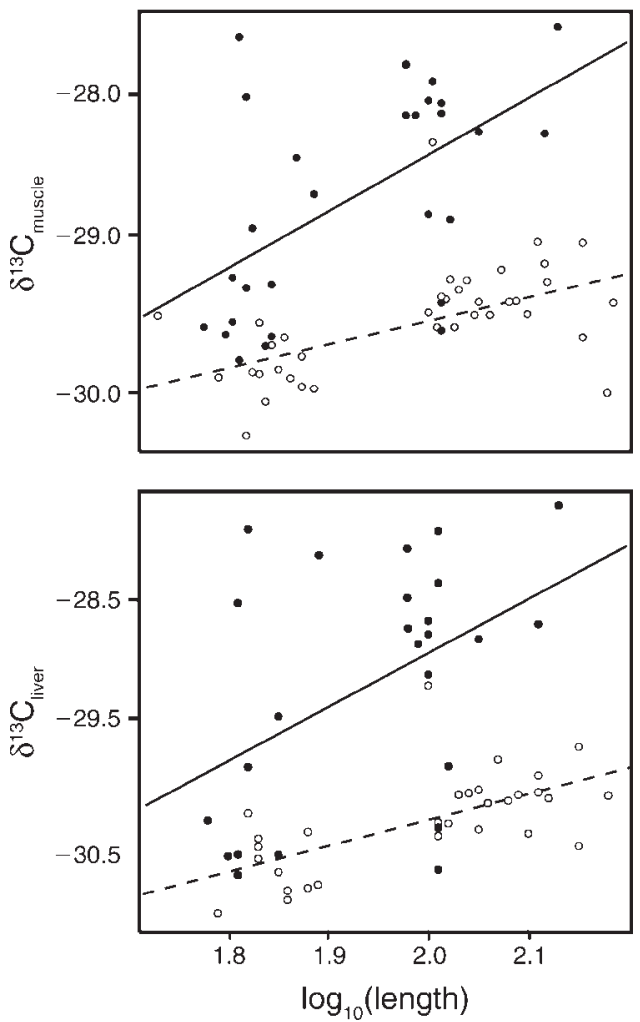

perch $\left(\mathrm{SD}=14\right.$ vs. 26 ; Fisher's $F$ test, $F_{24,30}=3.42, P=$ 0.002).

Pelagic and littoral perch showed low trophic niche overlap, depicted as $10 \%$ areal overlap of the convex hulls enclosing the values in the trophic position-littoral reliance bi-plot (Fig. 2C).

\section{Isotopic source proportions}

The isotopic signatures, end members, and the mixing polygon of the potential prey used with IsoSource are shown in Fig. 2B. The proportional contribution of zooplankton, benthic macroinvertebrates, and prey fish to isotopic signatures was markedly different between
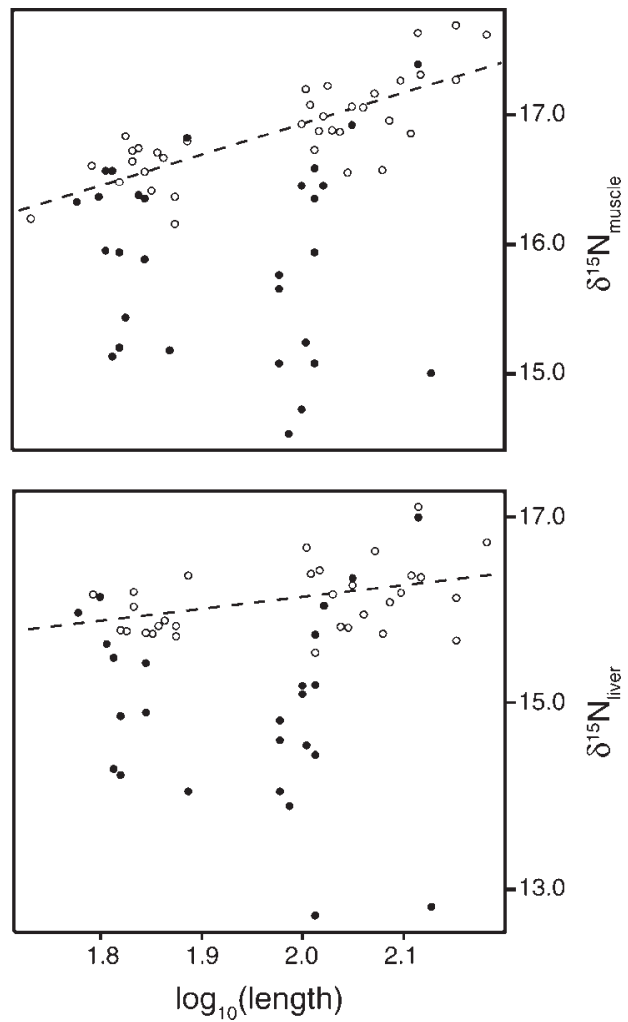

FIG. 3. Scatterplots corresponding to fitted linear models between $\delta^{13} \mathrm{C}, \delta^{15} \mathrm{~N}$, and $\log _{10}$-transformed perch length. Solid circles and lines correspond to littoral perch; open circles and dashed lines correspond to pelagic perch. Only significant slopes are shown. 
TABLE 3. Summary of trophic niche metrics (mean $\pm \mathrm{SD}$ ), and comparisons between pelagic and littoral perch.

\begin{tabular}{|c|c|c|c|c|c|c|c|}
\hline \multirow[b]{2}{*}{ Habitat } & \multirow[b]{2}{*}{$W$} & \multirow[b]{2}{*}{$W_{i}$} & \multirow[b]{2}{*}{$1-$ IS } & \multicolumn{2}{|c|}{ Muscle TA } & \multicolumn{2}{|c|}{ Liver TA } \\
\hline & & & & $\begin{array}{l}\text { Whole } \\
\text { data sets }\end{array}$ & $\begin{array}{c}50 \% \\
\text { subsets }\end{array}$ & $\begin{array}{l}\text { Whole } \\
\text { data sets }\end{array}$ & $\begin{array}{c}50 \% \\
\text { subsets }\end{array}$ \\
\hline Pelagic & 2.25 & $1.37 \pm 0.49$ & $0.44 \pm 0.24$ & 1.86 & 0.32 & 1.47 & 0.28 \\
\hline Littoral & 3.59 & $1.21 \pm 0.33$ & $0.66 \pm 0.10$ & 3.34 & 1.77 & 5.98 & 2.12 \\
\hline Statistics & $P=0.018$ & $\begin{array}{r}F_{1,48}=0.7 \\
P=0.42\end{array}$ & $\begin{array}{l}\chi_{1}^{2}=11.7 \\
P<0.001\end{array}$ & $P=0.035$ & $P=0.008$ & $P=0.002$ & $P=0.012$ \\
\hline
\end{tabular}

Notes: Definitions of variables: $W$, subpopulation diet breadth; $W_{i}$, individual diet breadth; 1 - IS, mean specialization index; TA, total area of the convex hulls that included the isotopic values in the $\delta^{13} \mathrm{C}-\delta^{15} \mathrm{~N}$ plot (whole data sets and $50 \%$ subsets to control for the influence of outliers); CD, distance of each individual to the isotopic centroid of its subpopulation; CVND, coefficient of variation of distances from each individual to its neighbors in the isotopic space. $P$ values of the differences between pelagic and littoral perch in $W$ and TA were estimated as the proportion of resampled data sets that exceeded the observed difference. $F$ values correspond to one-way ANOVAs, and $\chi^{2}$ values to Kruskal-Wallis tests.

littoral and pelagic perch, whereas the proportional contribution of benthic cladocerans was almost identical (Fig. 5). The pelagic perch showed higher proportions of zooplankton and prey fish, and much lower proportion of littoral macroinvertebrates (one-way ANOVAs, $F_{1,284}>4900, P<0.001$ in those three comparisons).

\section{DisCUSSION}

\section{Intrapopulation niche partitioning}

The use of different habitats led to marked intrapopulation niche partitioning in the generalist predator Eurasian perch. Niche partitioning confirmed our expectations given the differences in food chain properties between littoral and pelagic environments (e.g., Schindler and Scheuerell 2002). Stable isotope analyses showed that niche differences were stable from shorter (liver) to longer (muscle) periods of integration of trophic activity (Fig. 2A, Table 3). Trophic niche was much smaller in pelagic perch, and differences were consistent when controlled for the influence of outliers (TA; Fig. 2A, Table 3). In addition, isotopic metrics were consistent with the analyses of gut contents, which showed that short-term diet breadth was smaller in the pelagic subpopulation, while there were no differences in individual diet breadth between subpopulations (Table 3 ). This suggests that the habitat is responsible for the differences in diet breadth between subpopulations (probably because of lower prey diversity in the pelagic habitat), while individuals within subpopulations show similar trophic behavior. The lack of differences in individual diet breadth may be due to trade-offs or cognitive constraints limiting the efficient use of several different prey items simultaneously (Persson 1985, Bolnick et al. 2003, 2007).

In addition to the smaller trophic niche, pelagic fish showed much smaller distances to isotopic centroid (CD) than littoral fish, indicating lower trophic diversity within the subpopulation. As with niche width and diet breadth, isotopic metrics and gut contents analysis provided similar insights: the diet of the pelagic subpopulation was much less specialized ( 1 - IS; Table 3 ). Our use of the combination of niche metrics based on stable isotopes with conventional diet analyses provides a strong confirmation that more generalized populations can also be more heterogeneous (Van Valen 1965, Bolnick et al. 2007). We also found that pelagic perch showed lower azimuth variability in the vectors that connected the individual isotopic values of liver and muscle, suggesting more stable trophic behavior. Azimuths represent a bidimensional composite of the individual changes in $\delta^{13} \mathrm{C}$ $-\delta^{15} \mathrm{~N}$ between medium- and long-term integration of trophic activity. Hence, their variability reflects the degree of diet variability, either as a direct result of consuming prey with different isotopic signatures, or indirectly through differential individual fractionation in the consumer due to variation in the elemental composition of prey (Adams and Sterner 2000).

Pelagic and littoral perch also seemed to differ in the ontogenetic trajectories of resource use, reflected in different slopes in the relationship between $\delta^{13} \mathrm{C}$ and length found in muscle tissue. Perch undergoes ontogenetic diet shifts from zooplanktivory to zoobenthivory and piscivory, at successively larger stages (e.g., Hjelm et al. 2000). Our $\delta^{13} \mathrm{C}$ results suggested that reliance on littoral resources increased with fish size in both sub-

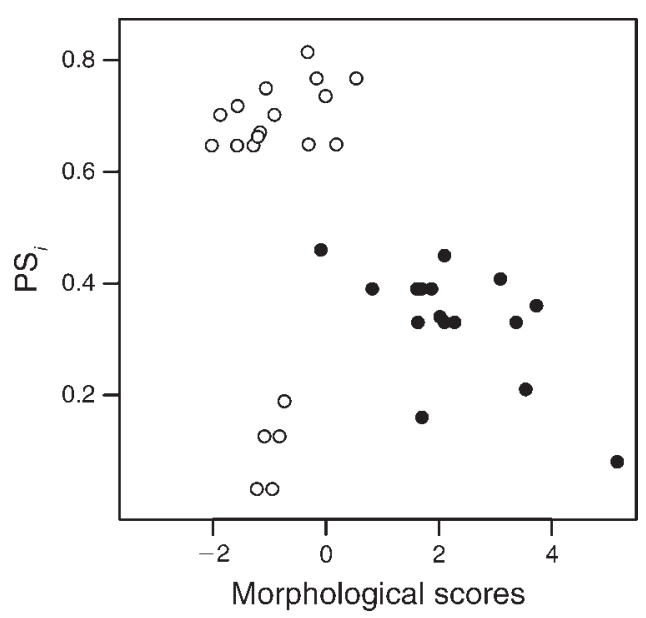

FIG. 4. Relationship between diet proportional similarity index $\left(\mathrm{PS}_{i}\right)$ and discriminant function analysis (DFA) morphological scores of pelagic (open symbols) and littoral (solid symbols) perch. 
TABLE 3. Extended.

\begin{tabular}{ccccc}
\hline \hline \multicolumn{2}{c}{ CD } & & \multicolumn{2}{c}{ CVND } \\
\cline { 1 - 2 } \cline { 5 - 5 } Muscle & Liver & & Muscle & Liver \\
\hline $0.46 \pm 0.27$ & $0.47 \pm 0.25$ & & $0.50 \pm 0.08$ & $0.54 \pm 0.10$ \\
$1.00 \pm 0.30$ & $1.26 \pm 0.62$ & & $0.53 \pm 0.12$ & $0.58 \pm 0.08$ \\
$\chi_{1}^{2}=32.0$, & $\chi_{1}^{2}=24.1$, & & $\chi_{1}^{2}=0.90$, & $\chi_{1}^{2}=1.13$, \\
$P<0.001$ & $P<0.001$ & & $P=0.34$ & $P=0.28$ \\
\cline { 1 - 3 } & & & & \\
\hline
\end{tabular}

populations, but the increase was faster in littoral perch (Fig. 3). We also found marked differences between subpopulations in the proportional contribution of resources to the average isotopic signatures, modeled with IsoSource (Fig. 5). The results suggested a much higher importance of fish in the diet of pelagic perch, consistent with their higher average trophic position. Trophic position is a continuous, integrative measure of the role of consumers in food webs (Vander Zanden and Rasmussen 1999). It adds robustness to our interpretation of niche differences related to differential food web structure between habitats. It may be speculated that higher reliance on piscivory by pelagic fish may be a response to the relatively smaller size of prey and less efficient energy transfer in the pelagic environment (Vander Zanden et al. 2006). Overall, we have provided evidence of intrapopulation partitioning of trophic niche structure related to habitat use, which was consistent over different timescales. Our results suggest that less diverse pelagic environments, often characterized by shorter food chains (Vander Zanden et al. 1999), provide fewer opportunities for individual specialization. However, it needs to be further investigated whether this relationship applies to other mobile generalist predators.

A marked reduction in niche width ("niche width collapse") has recently been found in a predatory fish due to habitat fragmentation (Layman et al. 2007b). We have shown here that substantial niche reduction could also occur in a generalist predator at the intrapopulation level. In our study, niche reduction was associated with differential habitat use, i.e., was not mediated by anthropogenic disturbance. However, the mechanism be- hind niche partitioning may be similar to that mediated by anthropogenic disturbances: lower prey diversity. We also showed that the niche metrics based on stable isotopes described and applied by Layman et al. $(2007 a, b)$ are useful at the intrapopulation level, and may also be used to estimate the degree of habitat coupling (see Diet specialization and habitat coupling). These metrics would probably vary with the structure, the relative extent, and the quality of the different habitats. Therefore, they may be used to assess the impact of disturbance on trophic processes.

\section{Trophic niche and morphology}

We found a relationship between the diet of fish and their morphology. In addition to the expected morphological difference already observed in previous studies (Svanbäck and Persson 2004, Eklöv and Svanbäck 2006), we found differences in the relationship between diet similarity $\left(\mathrm{PS}_{i}\right)$ and morphology in the two subpopulations (Fig. 4). The deeper bodied littoral individuals showed more specialized diets (lower $\mathrm{PS}_{i}$ values) than the more streamlined, whereas no relationship was found between morphology and $\mathrm{PS}_{i}$ in pelagic perch. These differences could be due to higher prey diversity in the littoral zone that allows larger morphological variation in the littoral fish, an explanation consistent with the wider niche and higher trophic diversity in this subpopulation (TA, CD; Table 3). Conversely, the lack of relationship between diet similarity and morphology in pelagic perch could be due to reduced prey diversity in the pelagic habitat, or simply to lower morphological variance in our sample. Although these results should be interpreted with care due to the small sample size, they illustrate how individual specialization and morphology could be related in environments that differ in resource diversity and availability.

\section{Diet specialization and habitat coupling}

The effective degree of habitat coupling mediated by predators may be limited by individual diet specialization. In lakes, it has been suggested that the use of both littoral and pelagic habitats by piscivorous fish could
FIG. 5. Box plots showing the distribution of feasible isotopic source proportions of prey contributing to muscle isotopic signatures of littoral (solid) and pelagic (open) perch. Boxes indicate the interquartile range of the data (i.e., 75 th percentile-25th percentile) and the position of the median; error bars extend to non-outlier data within 1.5 times the interquartile range. Source proportions were estimated with IsoSource (Phillips and Gregg 2003). Numbers within panels show the proportion of the potential diet groups in the gut contents of pelagic and littoral perch.

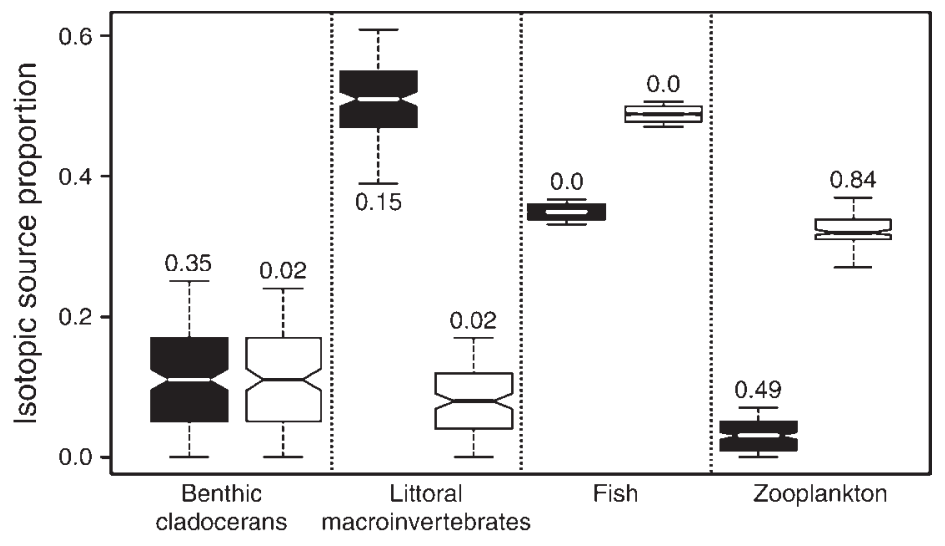


strengthen top-down control of pelagic and littoral food chains (Vadeboncoeur et al. 2005). This idea relied on the strong role of habitat coupling assigned to lake fish due to their mobility and overall strong reliance on littoral resources (Schindler and Scheuerell 2002, Vander Zanden and Vadeboncoeur 2002). Although the importance of the littoral production to fish species is well established (Hecky and Hesslein 1995, Vander Zanden and Vadeboncoeur 2002), our results suggest that both intrapopulation niche partitioning and distinct ontogenetic trajectories in the use of resources limit the degree of trophic linkage of pelagic and littoral food chains mediated by a generalist predator. The species as a whole uses both habitats, whereas individuals may specialize in spatially separated food chains. Intrapopulation differences in morphology and diet associated with habitat use (trophic polymorphism) seem to be widespread among fish species (Langerhans et al. 2003, Svanbäck et al. 2008). Hence, the limiting effect of trophic polymorphisms on the degree of habitat coupling may also be common. Understanding those effects in food webs has been limited by considering populations as ecologically homogeneous entities. In addition, individual diet specialization may also be partly responsible for the wide population-level variability in the littoral reliance of fish, which has been suggested to vary with abiotic factors such as lake size and basin shape (Vander Zanden and Vadeboncoeur 2002).

A quantitative, empirical measurement of the strength of habitat coupling seems to be lacking, even though it has been regarded as critical for food web stability (Schindler and Scheuerell 2002, Rooney et al. 2006). We suggest that the niche overlap of predatory species in the littoral reliance-trophic position space is a quantitative measure of the degree of ecological habitat coupling in a food web perspective. The axes of this space represent the origin of resources and the position of individuals in the transfer of energy from producers to top predators. In our study system, the areal niche overlap between pelagic and littoral fish derived from muscle isotopic signatures, i.e., longer-term integration of trophic activity, was $10 \%$ (Fig. 2C), and was consistent with the low overlap of fish morphology (Fig. 1). The period represented by this metric of habitat coupling depends on the actual period integrated by stable isotopes, which is itself a function of the turnover time of the tissue analyzed. In the muscle tissue of young perch this could be a period of several months $\left(\delta^{13} \mathrm{C}\right.$ average retention time $=1.5$ months; M. Quevedo, unpublished data). Therefore, the period encompassed by the relatively low value of habitat coupling that we found is relevant to primary and possibly secondary producers. Nonetheless, the degree of niche overlap between perch subpopulations likely varies due to the influence of population dynamics on the degree of individual specialization (Svanbäck and Persson 2004) and the plastic nature of perch morphology (Olsson and Eklöv 2005).
Perhaps full integration of spatially separated food chains may be a role for predators that occupy the highest trophic positions (Vander Zanden and Vadeboncoeur 2002). At least this has been suggested in ecosystems where top consumers are highly mobile and exploit resources across habitats (Hecky and Hesslein 1995, Rooney et al. 2006). However, the ontogenetic trajectories of isotopic signatures of perch in our study did not suggest that the trophic activity of larger individuals could provide full trophic convergence between pelagic and littoral habitats of lakes (Fig. 3). Furthermore, indications of substantial individual specialization inconsistent with a strong role in habitat coupling have been found in several lacustrine predators (reviewed in Bolnick et al. 2003). It seems pertinent to evaluate the assumption that large piscivore species effectively link spatially separated food chains, which together with the abiotic and biotic factors may determine coupling intensity.

\section{Methodological caveats}

The appeal of the stable isotopes technique may be evident due to its varied applications (West et al. 2006). Its ease of use may nonetheless be deceptive. There are several methodological caveats that could affect our results (e.g., Matthews and Mazumder 2004, Araújo et al. 2007, Martínez del Rio and Anderson-Sprecher 2008). The comparison of isotopic variance among consumers is susceptible to intrinsic prey variance, and may require inclusion in the analyses. However, this is no small task in a field study, as it would require an ambitious sampling scheme, specifically designed for prey, to assess their variability in both space and in time. Such variability should be evaluated as precisely as that of the focal consumer, and should include knowledge about prey fractionation and turnover time. In our study, we found no indication that isotopic signatures of littoral prey were intrinsically more variable than the pelagic ones (see Results: Isotopic signatures). We did find higher variability of isotopic signatures available to perch in the littoral zone (Fig. 2B), and the gut-content analyses of the diets confirmed that the diet of littoral fish was indeed more varied. To help with standardizing the intrinsic variability that might exist at the base of food webs, we analyzed long-lived primary consumers as isotopic end-members (Cabana and Rasmussen 1996, Post 2002) and used them to derive trophic position and littoral reliance. These transformations are comparable across different studies and ecosystems.

\section{Conclusions}

We showed that intrapopulation niche partitioning in generalist predators has implications for food web connectivity because it could limit the linkage of spatially separated food chains. Species that show the degree of intrapopulation niche differentiation that we found in Eurasian perch likely have a distinct effect on the trophic dynamics of their communities. This result 
reveals another facet of the complexity that characterizes food webs (Polis and Strong 1996), and illustrates the predictable impact that individual specialization may have on food webs (Bolnick 2003). Trophic linkage of food chains by predators has been regarded as critical for food web stability, although it is dependent on interaction strength (Schindler and Scheuerell 2002, Rooney et al. 2006). We speculate that the weak interactions between habitats mediated by perch subpopulations render a compartmented view of the lacustrine food web instead of a reticulate one (Pimm and Lawton 1980), which in turn would promote food web stability (Krause et al. 2003, Teng and McCann 2004). At any rate, our study underscores the importance of including individual specialization in food web models and empirical studies.

\section{ACKNOWLEDGMENTS}

We thank J. C. Olsson, T. Loreth, and A. Stenström for help in the field and laboratory. We also thank M. J. Bañuelos, J. C. Olsson, P. Laiolo, C. Martínez del Rio, T. E. Reimchen, and two anonymous reviewers for helpful comments and criticism on earlier versions of the manuscript. S. A. Carleton and C. Martínez del Rio kindly provided data and discussion on isotope retention times. Ronnie Lendrum edited the English. This research was funded by the EU Marie Curie IHP to M. Quevedo and the Swedish Research Council for Environment, Agricultural Science, and Spatial Planning (Formas) to P. Eklöv.

\section{Literature Cited}

Adams, T. S., and R. W. Sterner. 2000. The effect of dietary nitrogen content on trophic level ${ }^{15} \mathrm{~N}$ enrichment. Limnology and Oceanography 45:601-607.

Araújo, M., D. Bolnick, G. Machado, A. Giaretta, and S. dos Reis. 2007. Using $\delta^{13} \mathrm{C}$ stable isotopes to quantify individuallevel diet variation. Oecologia 152:643-654.

Barluenga, M., K. N. Stoelting, W. Salzburger, M. Muschick, and A. Meyer. 2006. Sympatric speciation in Nicaraguan crater lake cichlid fish. Nature 439:719-723.

Bolnick, D. I., R. Svanback, M. S. Araujo, and L. Persson. 2007. Comparative support for the niche variation hypothesis that more generalized populations also are more heterogeneous. Proceedings of the National Academy of Sciences (USA) 104:10075-10079.

Bolnick, D. I., R. Svanbäck, J. A. Fordyce, L. H. Yang, J. M. Davis, C. D. Hulsey, and M. L. Forister. 2003. The ecology of individuals: incidence and implications of individual specialization. American Naturalist 161:1-28.

Bolnick, D. I., L. H. Yang, J. A. Fordyce, J. M. Davis, and R. Svanbäck. 2002. Measuring individual-level resource specialization. Ecology 83:2936-2941.

Cabana, G., and J. B. Rasmussen. 1996. Comparison of aquatic food chains using nitrogen isotopes. Proceedings of the National Academy of Sciences (USA) 93:10844-10847.

Calenge, C. 2006. The package adehabitat for the R software: a tool for the analysis of space and habitat use by animals. Ecological Modelling 197:516-519.

de la Higuera, M., H. Akharbach, M. C. Hidalgo, J. Peragon, J. A. Lupianez, and M. Garcia-Gallego. 1999. Liver and white muscle protein turnover rates in the European eel (Anguilla anguilla): effects of dietary protein quality. Aquaculture 179:203-216.

Eklöv, P., and R. Svanbäck. 2006. Predation risk influences adaptive morphological variation in fish populations. American Naturalist 167:440-452.
Estes, J. A., M. L. Riedman, M. M. Staedler, M. T. Tinker, and B. E. Lyon. 2003. Individual variation in prey selection by sea otters: patterns, causes and implications. Ecology 72:144155.

France, R. L. 1995. Differentiation between littoral and pelagic food webs in lakes using stable carbon isotopes. Limnology and Oceanography 40:1310-1313.

Fry, B. 1988. Food web structure on Georges Bank from stable $\mathrm{C}, \mathrm{N}$, and $\mathrm{S}$ isotopic compositions. Limnology and Oceanography 33:1182-1190.

Futuyma, D. J., and G. Moreno. 1988. The evolution of ecological specialization. Annual Review of Ecology and Systematics 19:207-233.

Gotelli, N. J., and A. M. Ellison. 2004. A primer of ecological statistics. Sinauer, Sunderland, Massachusetts, USA.

Guelinckx, J., J. Maes, P. Van Den Driessche, B. Geysen, F. Dehairs, and F. Ollevier. 2007. Changes in $\delta^{13} \mathrm{C}$ and $\delta^{15} \mathrm{~N}$ in different tissues of juvenile sand goby Pomatoschistus minutus: a laboratory diet-switch experiment. Marine Ecology Progress Series 341:205-215.

Havens, K. E. 1997. Unique structural properties of pelagic food webs. Oikos 78:75-80.

Hecky, R. E., and R. H. Hesslein. 1995. Contributions of benthic algae to lake food webs as revealed by stable isotope analysis. Journal of the North American Benthological Society $14: 631-653$.

Hjelm, J., L. Persson, and B. Christensen. 2000. Growth, morphological variation and ontogenetic niche shifts in perch (Perca fluviatilis) in relation to resource availability. Oecologia 122:190-199.

Huxel, G. R., and K. McCann. 1998. Food web stability: the influence of trophic flows across habitats. American Naturalist 152:460-469.

Krause, A. E., K. A. Frank, D. M. Mason, R. E. Ulanowicz, and W. W. Taylor. 2003. Compartments revealed in foodweb structure. Nature 426:282-285.

Langerhans, R. B., C. A. Layman, A. K. Langerhans, and T. J. Dewitt. 2003. Habitat-associated morphological divergence in two Neotropical fish species. Biological Journal of the Linnean Society 80:689-698.

Layman, C. A., D. A. Arrington, C. G. Montaña, and D. M. Post. 2007a. Can stable isotope ratios provide for communitywide measurements of trophic structure? Ecology 88:42-48.

Layman, C. A., J. P. Quattrochi, C. M. Peyer, J. E. Allgeier, and K. Suding. 2007b. Niche width collapse in a resilient top predator following ecosystem fragmentation. Ecology Letters 10:937.

Martínez del Rio, C., and R. Anderson-Sprecher. 2008. Beyond the reaction progress variable: the meaning and significance of isotopic incorporation data. Oecologia 156:765-772.

Matthews, B., and A. Mazumder. 2004. A critical evaluation of intrapopulation variation of $\delta^{13} \mathrm{C}$ and isotopic evidence of individual specialization. Oecologia 140:361-371.

Maynard Smith, J. 1966. Sympatric speciation. American Naturalist 100:637-650.

Newsome, S. D., C. Martinez del Rio, S. Bearhop, and D. L. Phillips. 2007. A niche for isotopic ecology. Frontiers in Ecology and the Environment 5:429-436.

Olsson, J., and P. Eklöv. 2005. Habitat structure, feeding mode and morphological reversibility: factors influencing phenotypic plasticity in perch. Evolutionary Ecology Research 7: $1109-1123$.

Olsson, J., M. Quevedo, C. Colson, and R. Svanbäck. 2007. Gut length plasticity in perch: into the bowels of resource polymorphisms. Biological Journal of the Linnean Society 90:517-523.

Persson, L. 1985. Optimal foraging: the difficulty of exploiting different feeding strategies simultaneously. Oecologia 67: 338-341.

Persson, L., A. M. De Roos, D. Claessen, P. Byström, J. Lövgren, S. Sjögren, R. Svanbäck, E. Wahlström, and E. 
Westman. 2003. Gigantic cannibals driving a whole-lake trophic cascade. Proceedings of the National Academy of Sciences (USA) 100:4035-4039.

Phillips, D. L., and J. W. Gregg. 2003. Source partitioning using stable isotopes: coping with too many sources. Oecologia 136:261-269.

Pimm, S. L., and J. H. Lawton. 1980. Are food webs divided into compartments? Journal of Animal Ecology 49:879-898.

Pinnegar, J. K., and N. C. V. Polunin. 1999. Differential fractionation of $\delta^{13} \mathrm{C}$ and $\delta^{15} \mathrm{~N}$ among fish tissues: implications for the study of trophic interactions. Functional Ecology 13:225-231.

Polis, G. A., W. B. Anderson, and R. D. Holt. 1997. Toward an integration of landscape and food web ecology: the dynamics of spatially subsidized food webs. Annual Review of Ecology and Systematics 28:289-316.

Polis, G. A., and D. R. Strong. 1996. Food web complexity and community dynamics. American Naturalist 147:813-846.

Post, D. M. 2002. Using stable isotopes to estimate trophic position: models, methods, and assumptions. Ecology 83: 703-718.

Post, D., C. Layman, D. Arrington, G. Takimoto, J. Quattrochi, and C. Montaña. 2007. Getting to the fat of the matter: models, methods and assumptions for dealing with lipids in stable isotope analyses. Oecologia 152:179-189.

Quevedo, M., and J. Olsson. 2006. The effect of small-scale resource origin on trophic position estimates in Perca fluviatilis. Journal of Fish Biology 69:141-150.

R Development Core Team. 2008. R: A language and environment for statistical computing. R Foundation for Statistical Computing, Vienna, Austria.

Rohlf, F. J. 2005a. tpsRelw, relative warps analysis, version 1.42. Department of Ecology and Evolution, State University of New York at Stony Brook, New York, USA.

Rohlf, F. J. 2005b. tpsRegr, shape regression, version 1.31 . Department of Ecology and Evolution, State University of New York at Stony Brook, New York, USA.

Rooney, N., K. McCann, G. Gellner, and J. C. Moore. 2006. Structural asymmetry and the stability of diverse food webs. Nature 442:265-269.

Schindler, D. E., and M. D. Scheuerell. 2002. Habitat coupling in lake ecosystems. Oikos 98:177-189.

Schluter, D. 1996. Ecological speciation in postglacial fishes. Philosophical Transactions of the Royal Society B 351:807814.

Smith, T. B., and S. Skúlason. 1996. Evolutionary significance of resource polymorphisms in fishes, amphibians, and birds. Annual Review of Ecology and Systematics 27:111-133.

Svanbäck, R., and D. Bolnick. 2007. Intraspecific competition drives increased resource use diversity within a natural population. Proceedings of the Royal Society B 274:839-844.

Svanbäck, R., and P. Eklöv. 2002. Effects of habitat and food resources on morphology and ontogenetic growth trajectories in perch. Oecologia 131:61-70.
Svanbäck, R., and P. Eklöv. 2003. Morphology dependent foraging efficiency in perch: a trade-off for ecological specialization? Oikos 102:273-284.

Svanbäck, R., and P. Eklöv. 2006. Genetic variation and phenotypic plasticity: causes of morphological and dietary variation in Eurasian perch. Evolutionary Ecology Research 8:37-49.

Svanbäck, R., P. Eklöv, R. Fransson, and K. Holmgren. 2008. Intraspecific competition drives multiple species resource polymorphism in fish communities. Oikos 117:114-124.

Svanbäck, R., and L. Persson. 2004. Individual diet specialization, niche width and population dynamics: implications for trophic polymorphism. Journal of Animal Ecology 73:973982.

Teng, J., and K. S. McCann. 2004. Dynamics of compartmented and reticulate food webs in relation to energetic flows. American Naturalist 164:85-100.

Tieszen, L. L., T. W. Boutton, K. G. Tesdahl, and N. A. Slade. 1983. Fractionation and turnover of stable carbon isotopes in animal tissues: implications for $\delta^{13} \mathrm{C}$ analysis of diet. Oecologia 57:32-37.

Vadeboncoeur, Y., K. S. McCann, M. J. Vander Zanden, and J. B. Rasmussen. 2005. Effects of multi-chain omnivory on the strength of trophic control in lakes. Ecosystems 8:682693.

Vander Zanden, M. J., S. Chandra, S.-K. Park, Y. Vadeboncoeur, and C. R. Goldman. 2006. Efficiencies of benthic and pelagic trophic pathways in a subalpine lake. Canadian Journal of Fisheries and Aquatic Sciences 63:2608-2620.

Vander Zanden, M. J., and J. B. Rasmussen. 1999. Primary consumer $\delta^{15} \mathrm{~N}$ and $\delta^{13} \mathrm{C}$ and the trophic position of aquatic consumers. Ecology 80:1395-1404.

Vander Zanden, M. J., B. J. Shuter, N. Lester, and J. B. Rasmussen. 1999. Patterns of food chain length in lakes: a stable isotope study. American Naturalist 154:406-416.

Vander Zanden, M. J., and Y. Vadeboncoeur. 2002. Fishes as integrators of benthic and pelagic food webs in lakes. Ecology 83:2152-2161.

Vanni, M. J. 2002. Nutrient cycling by animals in freshwater ecosystems. Annual Review of Ecology and Systematics 33: 341-370.

Vanni, M. J., D. L. DeAngelis, D. E. Schindler, and G. R. Huxel. 2004. Overview: cross-habitat flux of nutrients and detritus. Pages 2263-2274 in G. A. Polis, M. E. Power, and G. R. Huxel, editors. Food webs at the landscape level. University of Chicago Press, Chicago, Illinois, USA.

Van Valen, L. 1965. Morphological variation and width of ecological niche. American Naturalist 99:377-390.

West, J. B., G. J. Bowen, T. E. Cerling, and J. R. Ehleringer. 2006. Stable isotopes as one of nature's ecological recorders. Trends in Ecology and Evolution 21:408-414.

Zelditch, M. L., D. L. Swiderski, H. D. Sheets, and W. L. Fink. 2004. Geometric morphometrics for biologists. Elsevier Academic Press, Burlington, Massachusetts, USA. 